\title{
A cross-contextual analysis of Iranian EFL teachers' attitudes and perceptions of critical thinking
}

Ghanizadeh, Afsaneh $\$
English Department, Imam Reza International University, Mashhad, Iran (a.ghanizadeh@imamreza.ac.ir)
Heydarnejad, Tahereh
English Department, Imam Reza International University, Mashhad, Iran (t.heydarnejad88@yahoo.com)

Received: 14 March 2015 Available Online: 6 June 2015
Revised: 25 March 2015 DOI: $10.5861 /$ ijrse.2015.1138

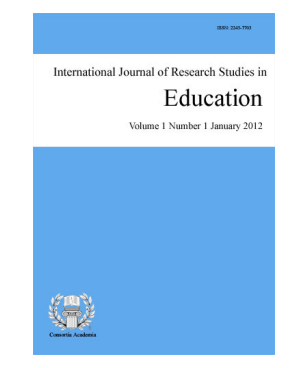

ISSN: 2243-7703 Online ISSN: 2243-7711

OPEN ACCESS

\section{Abstract}

The present paper explored EFL teachers' attitudes and perceptions toward critical thinking (CT). To do so, a three-phase study was designed. The first phase included an array of different steps to design and validate the 'EFL Teachers' Attitudes and Perceptions of Critical Thinking (CT)' scale. The scale comprised 20 items measuring attitudes to CT and 20 items measuring perceptions of CT. The results of confirmatory factor analysis (CFA) and reliability estimates demonstrated the acceptable validity and reliability indices. CFA also resulted in a more refined version of the scale. In the second phase, we utilized the validated questionnaire in two strikingly different milieus of language learning - formal (public high schools) vs. informal (private language institutes) - which differ in various respects. The findings of the second phase demonstrated significant differences between teachers' attitudes and perception toward CT in the two contexts. It was also found that teachers' attitudes and perceptions of CT differ neither by gender nor by teaching experience. Teachers' educational level, nevertheless, was found to play a significant role in their attitudes and perceptions of CT. In other words, teachers with higher educational degree (MA) tended to deploy more sophisticated attitudes and perceptions toward CT in comparison with their counterparts with BA degree. The results of semi-structures interviews with 8 high school and institute teachers substantiated the findings of the second phase.

Keywords: critical thinking (CT); attitudes to CT; perceptions of CT; EFL teachers; high schools; language institutes 


\section{A cross-contextual analysis of Iranian EFL teachers' attitudes and perceptions of critical thinking}

\section{Introduction}

Critical thinking (CT) offers the royal road to thinking which is generally considered as one of the most fundamental issues in the field of education. Critical thinking is associated with sophisticated thinking skills which in turn pave the way for attaining higher-order learning skills (Renner, 1996, as cited in Liaw, 2007). It is also considered to be a key element of higher levels of education or a principal objective of learning (Kuhn, 1999; Keeley \& Shemberg, 1995).

Socrates was the first one who brought into attention this method of thinking about two thousand years ago (Fisher, 2001); therefore, the concept of CT is not new. He believed that seeking reasons, obtaining evidence, questioning assumptions, analyzing concepts, and figuring out the implications of what was believed and acted upon were all necessary to justify one's claim. Based on the Socrates' ideas, the foundation of western philosophy was also erected by other Greek scholars such as Plato and Aristotle. In spite of the fact that CT has a long history, there is no agreed upon definition for it. For instance, John Dewey (1933), the father of modern critical thinking, defined it as active, regular, and prudent examination of ideas or premises based on existing evidence leading to convincing inferences (as cited in Fisher, 2001). He stated that aspects of critical thinking included evaluation, judgment, appraising beliefs and considering alternatives.

Along the same line of inquiry, Paul (1988) considered CT as "learning how to ask and answer questions of analysis, synthesis, evaluations, and information" (p. 50). Likewise, Ennis (1996) defended a conception of critical thinking rooted primarily in particular skills, such as observing, inferring, generalizing, reasoning, evaluating reasoning, and the like. Unlike the controversy over a unified definition for what constitutes critical thinking, there is a general consensus that critical thinking can be influential in almost every discipline and occupation, and it has also been found to be consistently required to meet all academic objectives (Facione \& Facione, 2006). To propose a more uncontroversial definition for CT, the American Philosophical Association conducted an all-encompassing project and conceptualized CT as purposeful and self-regulatory judgment leading to verification, inquiry, appraisal, and inference (Giancarlo \& Facione, 2001).

Leafing through the empirical studies conducted in the critical thinking domain in EFL contexts reveals a mounting attention toward critical thinking or higher-order thinking skills. For instance, Ghanizadeh and Moafian (2011) examined the relationship between EFL university students' critical thinking and emotional intelligence. The results substantiated an intricate interaction between the two variables in question. As they contented, at first glance, this finding may seem contrary to traditional beliefs which deemed improvements in emotional abilities deterrent to the development of cognitive and thinking abilities. They also pondered that this finding may appear inconsistent with prevailing stereotypes and misconceptions suggesting that thoughts and emotions are in conflict with each other or function independently. Their study, nevertheless, revealed students' emotional intelligence tends to better equip them with $\mathrm{CT}$ abilities.

In like manner, Fahim and Saeepor's (2011) study investigated the role of critical thinking on reading comprehension of Iranian EFL learners. An experimental study in an EFL context was conducted by Hashemi and Ghanizadeh (2012) to probe the influence of introducing and investigating critical discourse analysis (CDA) in reading journalistic text classes on the CT skills of ELT university students of Iran. The results indicated that CDA has a positive and significant impact on learners' critical thinking ability. CDA was also found to have the highest impact on two components of CT, interpretation and recognizing unstated assumption.

Children do not have innate capability to think critically, nor do they develop this ability without explicit 
A cross-contextual analysis of Iranian EFL teachers' attitudes and perceptions of critical thinking

instruction. Critical thinking has to be learnt, so teachers are all called upon to enhance in learners the ability to think critically (Hashemi \& Ghanizadeh, 2012). It is worth knowing that, the value put on higher-order thinking skills in current approaches to education is originated from the ideas of Dewey (1933). He contended that developing reflective and critical thinking skills must constitute the principal objective of education (as cited in Giancarlo \& Facione, 2001). So, schools should make any endeavor to "awaken, prompt, nurture and encourage the process of thinking critically and reflectively", as argued by Brookfield (1989). Davidson and Dunham (1996) noted that CT skills are teachable and can be developed by teachers through tasks and executed in the educational settings. In essence, it seems the integration of a number of programs into the educational curriculums is inevitable.

Key to the discussion, Elder and Paul (2003, p. 36) contended that it is an important part of critical thinking education to turn students into active questioners. They believed that it is important for learners to keep asking questions in the learning process, stressing that "to learn well is to question well" (p. 36). According to Mason (2008, p. 6), if teachers had a better understanding of the adaptive character of human reasoning, they would appreciate that students' logical reasoning also has to be trained in a domain-specific or context- sensitive way. Some educators have proclaimed not only the necessity for students to involve in regular and purposeful critical thinking, but also the basic ability of the students to develop self-awareness in what they are learning and why they are learning critical thinking (Bourdillon \& Storey, 2002).

Consistent with the above argument, Mayfield (2001) highlighted the importance of CT awareness in students' thinking process, emphasizing that teachers should spell out for the students the processes that they are involved in and the promising objectives underlying critical thinking. Children develop critical thinking when they are exposed to the opportunities to reason and evaluate (Smith, 1990, p. 107). Driven by the same concern, Mayfield (2001) maintained that in order to raise students' awareness of critical thinking, teachers should engage them actively in critical thinking activities and in dialogues with others so that they could reflect upon their own thinking and be conscious of their thinking processes through interactions and negotiation with others.

Despite the facilitative role teachers can play in developing students' CT skills, most teachers are still influenced by the traditional way of teaching. It means that they have put too much emphasis on what to think rather than how to think; they are too conscientious in giving the correct answers and students are not given too much room for free discussion. Involving students dynamically in critical thinking practices through the operative use of teacher-initiated questions, discussion, and reflection in a in a supportive atmosphere can pave the way the critical thinking skills and their critical attitudes (Rezaei et al., 2011). Along the same line of inquiry, Bourdillon and Storey (2002) notified that a mistake teachers frequently make in devising and asking questions is that students are not given sufficient time to ponder on challenging questions and appraise possible responses. Taking a similar path, Bourdillon and Storey (2002) pointed out that genuine communication should be the prime aim so that students' ideas are be heard, respected, and considered carefully. In doing so, Smith (1990) stated that critical thinking activities should be designed based on respect rather than power or exploitation.

Buskist and Irons (2008) explicated different reasons for which teachers and students shy away from thinking critically some of which are as follows: teachers' time and obligation pressure; demanding and imprecise nature of critical thinking assessment; students' reluctance of being coerced to think critically and teachers' concern over losing popularity as the result of these obligations; teachers' deficiency in critical thinking abilities; the intricate nature of critical thinking as opposed to the accustomed mode of learning by memorization, and students' lack of background knowledge required for reasoning and inference-making.

Despite all these student-teacher obstacles to teaching critical thinking, teachers can play a crucial role in developing critical thinking in their classes. Drawing from different reasons for teachers and students' reluctance to implement critical thinking, the present study focuses on the contextual specifics pertained to official and non-official settings accountable for EFL teaching in Iran. In particular, it seeks to scrutinize teachers' attitudes to $\mathrm{CT}$ and their perceptions of CT-associated practices in high schools (as representative of official milieus of 
Ghanizadeh, A., \& Heydarnejad, T.

English teaching) as well as language institutes (as liable for informal English teaching). It also intends to examine these attitudes and perceptions in relation to teachers' gender, teaching experience, and educational level. To this end, the following research questions are addressed in this study:

Q1. Is 'EFL teachers' attitudes and perceptions of $C T$ scale a valid and reliable tool?

Q2. Is there any significant difference between EFL teachers' attitudes and perceptions of CT across Official and Non-official contexts?

Q3. Is there any relationship between EFL teachers' attitudes and perceptions of CT and their gender?

Q4. Is there any relationship between EFL teachers' attitudes and perceptions of CT and years of teaching experience?

Q5. Is there any relationship between EFL teachers' attitudes and perceptions of CT and their educational level?

\section{Method}

This study was designed in three phases. In phase one, an instrument measuring 'EFL teachers' attitudes to $\mathrm{CT}^{\prime}$ as well as their 'perceptions of $\mathrm{CT}^{\prime}$ was designed and validated. It was then administered to a group of Iranian EFL teachers to determine its validity and internal consistency. The second phase of the study employed the validated scale in two different English learning contexts in Iran, namely, high schools and language institutes to explore disparities in teachers' attitudes and perceptions of CT. In this phase, the role of teachers' demographic variables in their attitudes and perceptions of CT was investigated. To complement the findings of the second phase a number of high school and institute teachers were interviewed during the third phase of the study.

\subsection{Participants}

The participants of the first phase comprised 146 EFL teachers (54 high school teachers, 92 institute teachers) teaching English in Mashhad. The participants of the second phase consisted of 36 EFL high school teachers (22 female, 18 male) and 37 EFL institute teachers teaching in Mashhad and Ghonabad, two cities in Northeast of Iran. The profile of the teachers is as follows: Their age varied from 23 to 48 years old, with 1-27 years of teaching experience and about educational level, 37 held an MA degree or were MA students, and 39 had a BA degree.

\subsection{Procedure}

To evaluate school and institute teachers' attitudes and perception toward CT, a questionnaire was designed (explained in more details in the results section). Having determined the validity and reliability estimates, it was distributed among high school and institute teachers. For the purpose of receiving reliable data, the researchers explained the aim of completing the questionnaire and assured the participants that their answers would be confidential; furthermore, the questionnaires were coded numerically and the participants were asked to answer it anonymously.

The second method employed for collecting data was an interview to delve deeper into the teachers' attitude and perceptions of CT. In doing so, eight teachers (4 school teachers and 4 institute teachers) were randomly selected for a semi-structured interviewed. They were told that their participation in the interview session was totally voluntary. Having agreed to take part in the interview session, they were asked four questions. The researchers recorded the interview. The responses were then transcribed for further analysis. The questions were as follows: 1) Do you think developing thinking skills, in particular critical thinking (present a definition here), is part of teachers' responsibility? 2) Do you think current curriculum, text books, and methods encourage critical thinking? 3) What do you do to enhance critical thinking in your classrooms? 4) Do you believe there is a need 
A cross-contextual analysis of Iranian EFL teachers' attitudes and perceptions of critical thinking for training courses on how to foster critical thinking in students?

\section{Results}

\subsection{Phase 1}

The first phase of the present study included an array of different steps to design and validate the 'EFL Teachers' Attitudes and Perceptions of Critical Thinking $(C T)^{\prime}$ scale. The researchers adopted Al-Nouh, Abdul-Kareem, and Taqi's (2014) scale measuring 'EFL Teachers' Attitudes toward Creativity and Their Perceptions of Practice'. Based on Watson-Glaser's conceptualization of CT, the scale was modified to accommodate critical thinking definition. The scale comprised 40 items measuring two separate modules: the first module consisted of 20 items seeking to elicit teachers' attitudes toward CT. Sample items include: 1) Critical thinking (CT) is an essential skill to be nurtured in schools; 2) EFL teachers should develop supplementary materials focusing on CT skills, and 3) The classroom should be a place where students feel free to question and evaluate. The items were arranged on a 5-point Likert ranging from 'strongly agree' to ' strongly disagree'. The second module comprised 20 statements targeted at exploring teachers' perceptions of their own CT-associated practices. Sample items are: 1) During discussion, I ask students questions to encourage them to think deeply about the topic; 2) I push students to evaluate what they have learned in varied situations, and 3) I prepare questions for my students to answer through inference-making.

Having written the questionnaire, a group of experts (a psychometrician, and three English educators) evaluated the quality of items in terms of clarity and comprehensiveness. Accommodating the experts' views and revision resulted in a more refined and comprehensible version of the scale. The designed questionnaire was then administered to 146 EFL teachers.

To determine the validity of the scale, a confirmatory factor analysis (CFA) utilizing the LISREL 8.50 statistical package was performed. Each module went through CFA separately. A number of fit indices were examined to evaluate the model fit: the chi square which should be non-significant, the chi square/df ratio which should be lower than 2 or 3, the root mean square error of approximation (RMSEA) of about .06 or .08, and the normed fit index $(N F I)$ and the good fit index $(G F I)$ with the cut value greater than 90 (Schreiber, Amaury, Stage, Barlow, \& King, 2006). The structural model for 'Attitudes to CT' is presented in Figure1. As indicated by Figure 1, the chi-square/dfratio (2.65) and the RMSEA (.072) reached the acceptable fit thresholds. The other two fit indices- GFI (.86) and NFI (.87)- were also very close to the acceptable criteria.

The indices on the lines indicate the standardized estimates and $t$-values, respectively. The first one is the standardized coefficient $(\beta)$ which demonstrates the factor loading of each item with respect to the corresponding factor and presents an easily grasped picture of effect size. The closer the magnitude to 1.0, the higher the correlation and the greater the factor loading of the item is. The magnitude of lower than 0.30 is an indication of weak factor loading; in such cases the item must be revised or discarded. The second measure is the $t$-value (t); if $t>2$ or $t<-2$, we call the result statistically significant. As the figure demonstrates, all items had accepted factor loading except items number $7(\beta=.08, t=.57)$, number $8(\beta=-.04, t=-.26)$, number $11(\beta=.13, t=.91)$, and number $12(\beta=.05, t=.34)$.

These four items which did not demonstrate good factor loading were omitted from the model. This resulted in a refined version of the scale comprising 16 items. Identical analysis was performed for the second module. The structural model for 'Perceptions of $\mathrm{CT}^{\prime}$ ' is shown in Figure 2. As indicated by Figure 2, the chi-square / $d f$-ratio (1.78), the RMSEA (.054), GFI (.88), and NFI (.89) all reached the acceptable fit thresholds. To check factor loadings of items, $\beta$ and $t$ values were examined. It was revealed that all items had accepted factor loading except item number $4(\beta=.20, t=1.55)$. So, this item was discarded. 


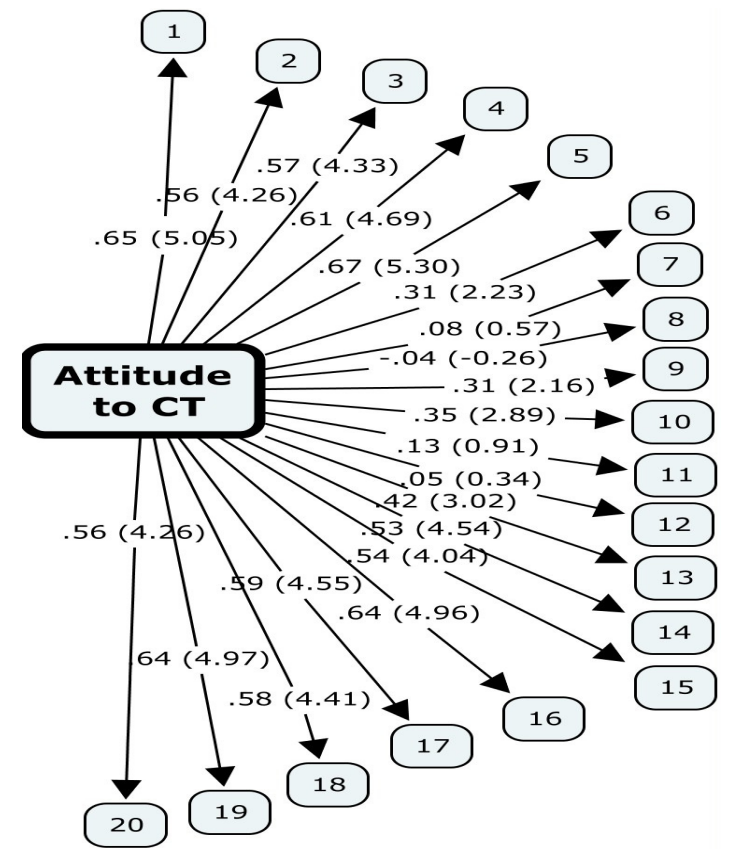

$\chi 2=372, d f=170, R M S E A=.072, G F I=.86, N F I=.87$

Figure 1. The schematic representation of attitudes to CT and the corresponding items

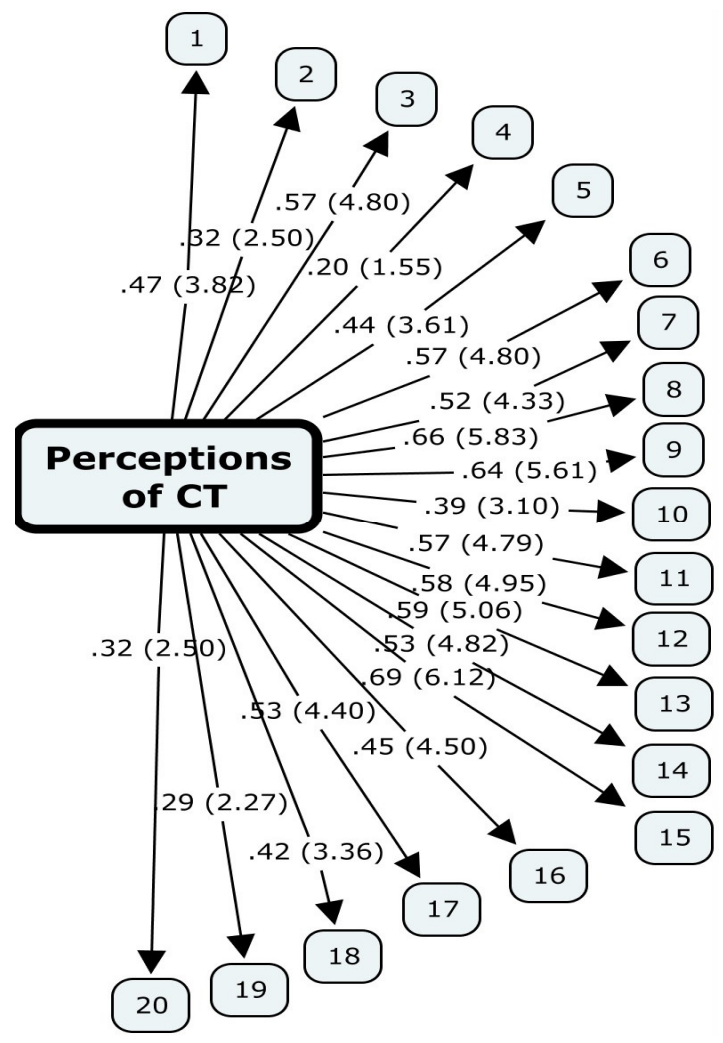

$\chi 2=304.99, d f=170, R M S E A=.054, G F I=.88, N F I=.89$

Figure 2. The schematic representation of perceptions of CT and the corresponding items 
A cross-contextual analysis of Iranian EFL teachers' attitudes and perceptions of critical thinking

The reliability estimates computed via the Cronbach's alpha for the first module (comprising 16 items) and the second module (comprising 19 items) were found to be .818 and .855 , respectively.

\subsection{Phase 2}

To decide whether teachers' attitudes and perceptions of CT differ across official (high schools/ denoted as setting 1) and non-official (language institutes/ denoted as setting 2) contexts, an independent-samples $t$-test was applied to the data. Table 1 summarizes the descriptive results of Attitudes in the two settings. As the table shows, the mean scores of Attitudes across the two settings are different: Setting $1(M=64.61, S D=8.13)$, Setting 2 $(M=66.78, S D=8.15)$.

\section{Table 1}

Descriptive Statistics of Attitudes to CT in Settings 1 and 2

\begin{tabular}{lccccc}
\hline & Setting & $\mathrm{N}$ & Mean & SD & Std. Error Mean \\
\hline \multirow{2}{*}{ Attitudes to CT } & 1.00 & 36 & 62.3889 & 8.41522 & 1.40254 \\
& 2.00 & 37 & 67.3243 & 8.21940 & 1.35126 \\
\hline
\end{tabular}

To see whether this observed difference is significant statistically, the results of $t$-test presented in Table 2 were examined. As the table indicates, there is a statistically significant difference between the two groups (high school teachers vs. institute teachers) regarding their Attitudes to CT $(t=-2.353, p<.05)$. This can be figured out by examining the magnitude of $t$ which should be higher than that of critical $t$, and the amount of $p$-value which should be lower than 0.05 .

\section{Table 2}

The Results of Independent T-Test for Determining Cross-contextual Differences in Attitudes to CT

\begin{tabular}{cccccc}
\hline & $\mathrm{t}$ & $\mathrm{df}$ & Sig. (2-tailed) & Mean difference & Std. error difference \\
\hline Attitudes to CT & -2.535 & 71 & .013 & -4.93544 & 1.94693 \\
\hline
\end{tabular}

Identical analysis was performed for Perceptions of CT. The results of $t$-test are represented in Table 3. As the table indicates, there is a statistically significant difference between the two groups regarding their Perceptions of CT $(t=-2.353, p<.05)$.

Table 3

The Results of Independent T-Test for Determining Cross-contextual Differences in Perceptions of CT

\begin{tabular}{cccccc}
\hline & $\mathrm{t}$ & $\mathrm{df}$ & Sig. (2-tailed) & Mean difference & Std. error difference \\
\hline Perceptions of CT & -2.693 & 70 & .009 & -5.26255 & 1.95442 \\
\hline
\end{tabular}

To investigate the role of gender in Attitudes to CT as well as Perceptions of CT, independent-samples $t$-tests were utilized. The results are presented in Table 4.

\section{Table 4}

The Results of Independent T-Tests for Determining Gender Differences in Attitudes and Perceptions

\begin{tabular}{lccccc}
\hline & $\mathrm{t}$ & $\mathrm{df}$ & Sig. (2-tailed) & Mean Difference & $\begin{array}{c}\text { Std. Error } \\
\text { Difference }\end{array}$ \\
\hline Attitudes to CT & .109 & 71 & .914 & .22778 & 2.09024 \\
Perception of CT & -.088 & 71 & .930 & -.18968 & 2.16335 \\
\hline
\end{tabular}

As Table 4 reveals, EFL teachers' Attitudes to CT as well as their Perception of CT are not different across male and female teachers: Attitudes $(t=.109, p<.05)$, Perception $(t=-.088, p<.05)$. 
Ghanizadeh, A., \& Heydarnejad, T.

To examine the relationship between EFL teachers' Attitudes to CT as well as their Perception of CT and years of teaching experience, Pearson Coefficient correlation was conducted. The results presented in Table 5 indicated that teachers' Attitudes and Perceptions of CT do not correlate with their teaching experience: Attitudes $(r=-.121, p<.05)$, Perception $(r=-.125, p<.05)$.

\section{Table 5}

The Results of Correlations between Teaching Experience, Attitudes, and Perception

\begin{tabular}{lc}
\hline & Teaching experience \\
\hline Attitudes to CT & -.121 \\
Perceptions of CT & -.125 \\
\hline
\end{tabular}

The last research question sought to explore the role of teachers' educational level in their Attitudes and Perceptions of CT. Table 6 shows the descriptive statistics of Attitudes and Perceptions of CT with regard to teachers' educational level, i.e., teachers with BA or MA degrees. As it can be seen, teachers with MA degree exhibited higher mean scores of both Attitudes to CT $(M=67.02, S D=10)$ and Perceptions of CT $(M=76.97$, $S D=9.22)$.

\section{Table 6}

Descriptive Statistics of Attitudes and Perceptions across Teachers with BA and MA

\begin{tabular}{lccccc}
\hline & Degree & N & Mean & SD & Std. Error Mean \\
\hline \multirow{2}{*}{ Attitudes to CT } & BA & 39 & 63.0256 & 6.80359 & 1.08945 \\
& MA & 34 & 67.0294 & 10.00753 & 1.71628 \\
\hline \multirow{2}{*}{ Perceptions of CT } & BA & 39 & 72.4615 & 8.20092 & 1.31320 \\
& MA & 34 & 76.9706 & 9.22935 & 1.58282 \\
\hline
\end{tabular}

To see whether the above differences obtained via descriptive statistics were significant statistically, independent-samples $t$-tests were applied to the data. The results indicated educational level plays a significant role for both Attitudes to CT $(t=-2.021, p<.05)$ and Perception of CT $(t=-2.210, p<.05)$

Table 7

The Results of Independent T-Test for Determining the Role of Level in Attitudes and Perception

\begin{tabular}{lccccc}
\hline & $\mathrm{t}$ & $\mathrm{df}$ & Sig. (2-tailed) & Mean Difference & $\begin{array}{c}\text { Std. Error } \\
\text { Difference }\end{array}$ \\
\hline Attitudes to CT & -2.021 & 71 & .047 & -4.00377 & 1.98155 \\
Perception of CT & -2.210 & 71 & .030 & -4.50905 & 2.03992 \\
\hline
\end{tabular}

\subsection{Phase 3}

To get a more profound insight into school and institute teachers' attitudes to CT as well as their perceptions of CT, a semi-structure interview was conducted with 4 school teachers (ages 32-42, 3 female, 1 male, 3 MA, 1 BA) and 4 institute teachers (ages 30- 36, 2 female, 2 male, 3 MA, 1 BA) .

The first interview question asked whether developing thinking skills, especially critical thinking is part of teacher's responsibility. Among the school teachers, two of them agreed but the other two believed that while the teacher themselves are not qualified enough and do not know how to use thinking skills, they cannot nurture it in their students effectively. On the other hand, all 4 institute teachers put emphasize on their responsibility to develop thinking skills in order to help students internalized the subject matter and to avoid rote learning.

School teachers' idea toward the second question asking them whether the current curriculum, texts, books and methods encourage critical thinking was totally different from the second group, i.e., institute teachers. They believed their school English curriculum neither encourages critical thinking nor prepares the proper context for 
A cross-contextual analysis of Iranian EFL teachers' attitudes and perceptions of critical thinking

its stimulation. Books are mainly based on mechanical drills and language skills in isolation. Despite the methodological developments in the field of foreign language teaching, most of the teachers are still using traditional teaching methods. Teachers in institutes, nevertheless, pointed out to the learner-centered nature of language institutes which entails using new and interesting books for teaching and trying to use competent teachers and new technologies to improve language learning as much as possible.

As the two groups were asked to mention what they do to enhance critical thinking in their classes, most of them confirmed that if there is an opportunity for a teacher to change the teaching methodology according to students' needs and preferences, their interest and curiosity to the subject matter will be fostered. Teachers in high schools stated that what they do consists of asking questions requiring inference-making and deduction. The teachers in institutes also pointed to this requirement and added they try to develop their student's thinking skills by providing them with appropriate supplementary materials; materials which entail reflectivity, evaluation of arguments, reasoning, and problem solving. These supplementary materials, as they stated, encompass reading extracts, journalistic texts, audio and video excerpts, etc.

As the final question, they were asked about the need for training courses on different thinking skills especially CT. All the teachers in both groups believed that training courses are beneficial. As it was mentioned before, some school teachers believed that the gap for CT in English learning classes refers to lack of enough knowledge about it on the part of teachers. While they do not know exactly the meaning of CT and different strategies which will contribute to the better understanding of the text and tasks, how they can apply it in their classrooms.

\section{Discussion}

The primary aim of the present study was to design and validate a scale for measuring EFL teachers' attitudes to CT and their perceptions of CT-associated practices. To do so, a 40- item questionnaire was designed based on 'EFL Teachers' Attitudes toward Creativity and Their Perceptions of Practice' scale and revolving around Watson-Glaser's conceptualization of CT. It consisted of two modules: the first module comprised 20 items seeking to elicit teachers' attitudes toward CT. The second module comprised 20 statements targeted at exploring teachers' perceptions of their own CT-associated practices. The results of CFA and reliability estimates demonstrated that the scale had good model fit with the empirical data. In other words, the scale enjoyed acceptable validity and reliability indices.

Through the second phase of the study, the researchers employed the validated scale in two dramatically different milieus for language learning in Iran to examine cross-contextual discrepancies in EFL teachers' attitudes and perceptions of CT. It was assumed these two environments deviate significantly from each other in every important respect, such as English learning objectives, teaching methods, teachers and learner roles, and the number of students. So, the researchers conjectured that these differences in turn might influence teachers' attitudes and perceptions of CT. The results confirmed the hypothesis formulated in this study that teachers teaching at these two sectors have different attitudes and perceptions toward instructing and implementing activities, tasks, and practices which are believed to enhance CT in language classes. In particular, it was found institute teachers tend to adopt more favorable attitudes to $\mathrm{CT}$ as well as more affirmative perceptions of their CT- associated practices.

This finding in not unexpected if we contemplate on the principal structures of these two language leaning environments. The English learning curriculum in high schools is derived from the traditional grammar translation approaches and is presented by the Ministry of Education. The syllabus is usually inflexible and uniform across the country and all through the prevailing high school majors (Math, Science, and Humanities). Furthermore, the English courses are mandatory to pass in order to graduate and ultimately get diploma. Teacher has the central role and learners are considered as receivers of information, listeners, and imitators. Indeed the method of language teaching involves a passive form of learning where students are not required to examine 
their own feelings, thoughts and understandings in response to the subject material. In this traditional mode of teaching, teachers tends to impose rigid and less flexible ways of managing students and their concerns, and they stick to the course book and to their predetermined syllabi and are reluctant to embrace change and variety. As a result, they feel less obliged to devise and execute creative and reflective tasks and activities requiring active engagement and critical appraisal of the information on the part of students.

Language institutes, on the other hand, are private non-profitable organizations which present courses aligned with the most recent language learning methods and approaches. These language institutes are typically conducted based on CLT (communicative language teaching) and TBLT (task-based language teaching). The principal features of these L2 teaching methods pivots around interaction (whole-class, group, or pair-work), discovery learning, and learners' personal experience and active engagement. In classes conducted by these teaching methods, teachers and learners work together, and the boundaries between teachers and learners are not as formal and inflexible as classes conducted by traditional-oriented approaches. This in turn entails adopting more learner-centered and discovery-learning approaches in teaching. What's more, in such classes maintaining learners' interest and having them engaged in class activities which address higher-order abilities are of prime importance. This necessitates teachers' creative thinking and active engagement in addressing a variety of learning styles, thinking up reflective and evaluative tasks, and developing supplementary materials including audio visual materials and realia.

The results of the second phase of the study demonstrated that these attitudes and perceptions do not differ with teachers' teaching experience and their gender. In other words, male and female teachers reported identical attitudes and perceptions toward CT. Furthermore, as the years of teaching pass, teachers do not seem to develop different attitudes and perceptions of CT. On the other hand, it was found teachers with higher educational degree (MA) tend to deploy more sophisticated attitudes and perceptions toward CT in comparison with their counterparts with BA degree. Based on this finding, it appears teachers who further their education and participate in graduate programs appreciate the prominence of developing higher-order thinking skills in their students. This can be due to the fact that graduate courses are typically discussion-based and contemplative rooted primarily in interpreting, inferring, generalizing, reasoning, and evaluating reasoning. What's more, participants in graduate programs are commonly exposed to current approaches of education highlighting the status of higher-order thinking skills as the core objective of schooling.

Based on the findings of the present study, EFL teachers (in particular high school teachers) are recommended to take into account the significance of developing their students' thinking skills. They are also expected to become cognizant of this fact that CT skills could be taught as part of EFL instruction and EFL teachers can play an influential role in structuring activities and techniques which cultivate and promote EFL learners' CT abilities.

As an illustration of CT-developing practices, Buskist and Irons (2008) proposed five ways for instructing critical thinking:

$>$ Provide students with problems to analyze or solve in the class or at home.

$>\quad$ Provide students with effective critical thinking techniques.

$>$ Adjust these techniques in your subject matter so that you can scaffold effective critical thinking for your students.

$>\quad$ Bring to class some of everyday examples of critical thinking which are relevant to your subject matter.

$>$ Give your students ample opportunity to put into practice what they have gained via these techniques.

In the realm of EFL education, Ghanizadeh and Mirzaee (2012) in a book entitled "Critical thinking: how to 
A cross-contextual analysis of Iranian EFL teachers' attitudes and perceptions of critical thinking enhance it in language classes" proposed several techniques and strategies for promoting critical thinking in language classes. The techniques comprised: concept mapping, critical discourse analysis, argumentation, emotion regulation practices, and reflective journals. In the book, these techniques were first introduced in sequence; the procedures on how to integrate each of these programs into language classes were then presented. Taken together, EFL teachers can make use of these step-by-step and accessible procedures to equip language learners with essential skills required to think critically. As the final remark, it is worth highlighting that in-service teacher training programs can pave the way for providing teachers with skills and knowledge necessary to implement in their classes in order to develop their students' CT skills.

\section{References}

Al-Nouh, N. A., Abdul-Kareem, M. M., \& Taqi, H. A. (2014). Primary school EFL teachers' attitudes towards creativity and their perceptions of practice. English Language Teaching, 7(9), 74-90. http://dx.doi.org/10.5539/elt.v7n9p74

Bourdillon, H., \& Storey, A. (2002). Aspects of teaching and learning in secondary schools: Perspectives on practice. London: Routledge Falmer.

Brookfield, S. (1987). Developing critical thinking. New York: Milton Keynes.

Buskist, W., \& Irons G. J. (2008). Simple strategies for teaching your students to think critically. In D. S. Dunn, J. S. Halonen, \& R. A. Smith (Eds.), Teaching critical thinking in psychology: A handbook of best practices (pp. 49-57). UK: Blackwell Publishing Ltd. http://dx.doi.org/10.1002/9781444305173.ch5

Dantas-Whitney, M. (2002). Critical reflection in the second language classroom through audiotaped journals. System, 30(4), 543-555. http://dx.doi.org/10.1016/S0346-251X(02)00046-5

Davidson, B. (1998). A case for critical thinking in the English language classroom. TESOL Quarterly, 32(1), 119-123.

Davidson, B., \& Dunham, R. (1997). Assessing EFL student progress in critical thinking with the Ennis-Weir critical thinking essay test. JALT Journal, 19(1), 43-57. http://dx.doi.org/10.2307/3587906

Dewey, J. (1933). How we think: A restatement of the relation of reflective thinking to the educational process. D.C. Heath, Lexington, MA.

Elder, L., \& Paul, R. (2003). Critical thinking: Teaching students how to study and learn. Journal of Developmental Education, 27(1), 36-37.

Ennis, R. (1996). Critical Thinking. New York: Prentice-Hall.

Facione, N. C., \& Facione, P. A. (1996). Externalizing the critical thinking in knowledge development and critical judgment. Nursing Outlook, 44(3), 129-136. http://dx.doi.org/10.1016/S0029-6554(06)80005-9

Facione, P. A., Giancarlo, C. A., Facione, N. C., \& Gainen, J. (1995). The disposition toward critical thinking. Journal of General Education, 44(1), 1-25.

Fahim, M., \& Sa'eepour, M. (2011). The impact of teaching critical thinking skills on reading comprehension of Iranian EFL learners. Journal of Language Teaching and Research, 29(4), 867-874. http://dx.doi.org/10.4304/jltr.2.4.867-874

Fairclough, N. (1989). Language and power. Longman, London.

Fisher, A. (2001). Critical thinking: An introduction. Cambridge: Cambridge university press.

Ghanizadeh, A. (2011). An investigation into the relationship between self-regulation and critical thinking among Iranian EFL teachers. The Journal of Technology \& Education, 5(3), 213-221.

Ghanizadeh, A., \& Mirzaee, S. (2012). Critical thinking: how to enhance it in language classes. Germany: LAP.

Ghanizadeh, A., \& Moafian, M, (2011). Critical thinking and emotional intelligence: Investigating the relationship among EFL learners and the contribution of age and gender. Iranian Journal of Applied Linguistics, 14(1), 23-48.

Giancarlo, C. A., \& Facione, P. A. (2001). A look across four years at the disposition toward critical thinking among undergraduate students. Journal of General Education, 50(1), 29-55. http://dx.doi.org/10.1353/jge.2001.0004

Hashemi, M. R., \& Ghanizadeh, A. (2012). Critical discourse analysis and critical thinking: An experimental. 
Ghanizadeh, A., \& Heydarnejad, T.

System, 40(1), 37-47. http://dx.doi.org/10.1016/j.system.2012.01.009

Kealey, B. T., Holland, J., \& Watson, M. (2005). Preliminary evidence on the association between critical thinking and performance in principles of accounting. Issues in Accounting Education, 20(1), 33-49. http://dx.doi.org/10.2308/iace.2005.20.1.33

Keeley, S., \& Shemberg, K. (1995). Coping with student resistance to critical thinking, College Teaching, 43(4), 140-147. http://dx.doi.org/10.1080/87567555.1995.9925537

Kuhn, D. (1999). A developmental model of critical thinking. Educational Researcher, 28(2), 16-26. http://dx.doi.org/10.3102/0013189X028002016

Liaw, M. L. (2007). Content-based reading and writing for critical thinking skills in an EFL context. English Teaching \& Learning, 31(2), 45-87.

Mason, M. (2008). Critical thinking and learning. Oxford: Blackwell Publishing. http://dx.doi.org/10.1002/9781444306774

Mayfield, M. (2001). Thinking for yourself: Developing critical thinking skills through reading and writing (5th ed.). London: Harcourt College.

Moon, J. (2008). Critical thinking: An exploration of theory and practice. London: Routledge.

Oliver, H., \& Utermohlen, R. (1995). An innovative teaching strategy: Using critical thinking to give learners a guide to the future. Retrieved from http://files.eric.ed.gov/fulltext/ED389702.pdf

Paul, R. (1988). Critical thinking in the classroom. Teaching $K-8,18,49-51$.

Pennycook, A. (1994). The cultural politics of English as an international language. London: Longman.

Renner, C. E. (1996). Enrich learners' language production through content-based instruction. Paper presented at the National Conference on Lingua eNuova Didattica, Modena, Italy.

Rezaei, S., Derakhsan, A., \& Bagherkazemi, M. (2011). Critical thinking in language education. Journal of Language Teaching and Research, 2(4), 769-777. http://dx.doi.org/10.4304/jltr.2.4.769-777

Schreiber, J. B., Amaury, N., Stage, F. K., Barlow, E. A., \& King, J. (2006). Reporting structural equation modeling and confirmatory factor analysis results: A review. Journal of Educational Research, 99(6), 323-337. http://dx.doi.org/10.3200/JOER.99.6.323-338

Smith, F. (1990). To think. New York: Teachers College Press.

Yuretich, F. R. (2004). Encouraging critical thinking: Measuring skills in large introductory science classes. Journal of College Science Teaching, 33(3), 40-46. 